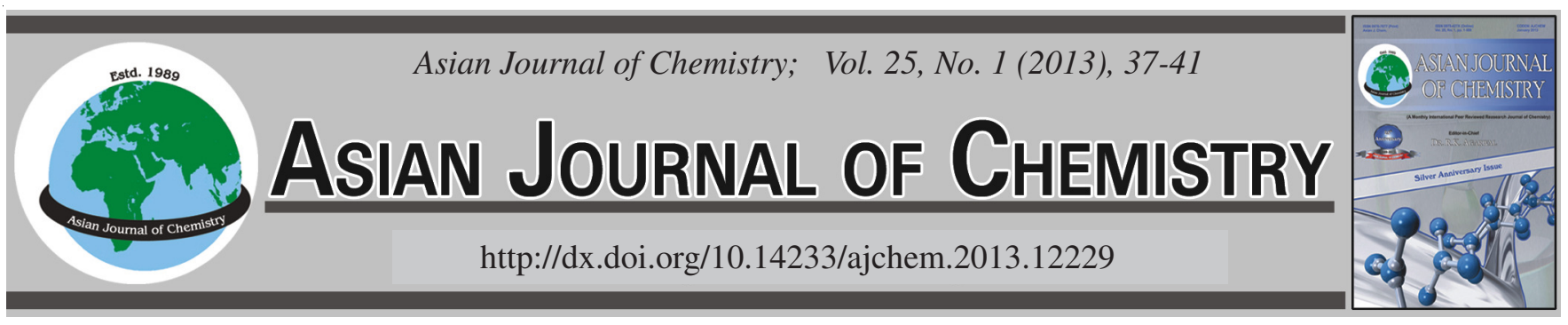

\title{
Optimized EDTA Washing Procedure to Decontaminate Heavy Metals from Soils in Iron and Steel Works Sites
}

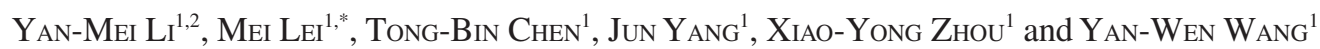

\begin{abstract}
${ }^{1}$ Institute of Geographic Sciences and Natural Resources Research, Chinese Academy of Sciences, Beijing 100101, P.R. China
\end{abstract} ${ }^{2}$ Graduate University of Chinese Academy of Sciences, Beijing 100049, P.R. China

*Corresponding author: E-mail: leim@igsnrr.ac.cn; liyanmei0101@163.com

(Received: 18 June 2011;

\begin{abstract}
The removal of heavy metal ions from the soil of iron and steel work site with EDTA enhanced washing was investigated through a series of laboratory tests to examine the effect of EDTA concentration, washing time, washing cycles and physical sieving. The heavy metal species in the soil before and after EDTA washing were examined by the sequential extraction procedure. The results are based on comprehensive consideration of associated factors such as high heavy metal removal rates, low loss of soil mineral elements and proper $\mathrm{pH}$ value of washing solution, EDTA concentration was controlled around $0.075 \mathrm{mmol} \mathrm{g}^{-1}$. Considering the heavy metal removal rates and its increasing extent, the washing time and cycles were kept at about $3 \mathrm{~h}$ and 3 cycles respectively. Screening out the soil with size of 1-2 mm from the buck soil reduced soil volume by $21.7 \%$. However, the heavy metal removal rates were not significantly reduced. This made EDTA washing economically viable. Under the optimum conditions, a total of 91.7, 35.5 and $21.4 \%$ of $\mathrm{Zn}$, Cd and As, respectively, could be removed from the soil, mainly came from the Fe/Mn fraction (48-82 \%). With the lower initial concentration in contaminated soil, $\mathrm{Cd}$ and As were more tightly bound to soil particles, which resulted in greatly lower removal rates of $\mathrm{Cd}$ and $\mathrm{As}$ than $\mathrm{Zn}$. The operationally defined fraction results indicated that heavy metals in the soil after EDTA washing occurred mainly in residue bound fraction (62-68 \%) and lowest in exchangable fraction (lower than $0.4 \%$ ), to explain that the heavy metal availability in the washed soil did not increase. The results implied that EDTA washing could be used to remediate heavy metal contaminated soil of the iron and steel work site. However, careful control of the process parameters of EDTA washing should be considered to minimize the mobility of the remaining heavy metals.
\end{abstract}

Key Words: Heavy metals, Iron and Steel work sites, EDTA, Particle size separation, Metal fraction.

\section{INTRODUCTION}

Large extensions of contaminated iron and steel work sites are not suitable for reuse unless a suitable remediation technique was adopted. These sites were severely contaminated with heavy metals derived from industrial activity over past decades ${ }^{1}$. Since heavy metals are toxic to ecosystem and do not degrade themselves, they must be treated to reduce their bioavailability or taken out from the soil ${ }^{2}$.

Soil washing has been considered as one of the most suitable remediation techniques for the treatment of soils polluted with heavy metals ${ }^{3}$. It involves separating metals from the solid phase to a liquid matrix by dissolving them with promising washing agents or concentrating metals into a small volume of soil via separating them from sand fractions ${ }^{4,5}$. It is relatively simple, effective and time-saving, has been successfully applied in large projects ${ }^{6}$.

EDTA represents one of attractive washing agents for metal-contaminated soils ${ }^{7}$. It has strong chelating ability and effective in removing $\mathrm{Pb}, \mathrm{Zn}$ and $\mathrm{Cd}$ from contaminated soils ${ }^{8,9}$, has low toxicity and no bioaccumulation in living organisms through the food chain ${ }^{10}$. In addition, it would cause minor impact on the physical and chemical properties of the soil matrix compared to acids ${ }^{11}$. More importantly, it is low biodegradable, can be recovered and reused ${ }^{2}$.

Process parameter is the only variable that affecting the efficiency and cost of EDTA washing technique since soil and metal related parameters are fixed ${ }^{12}$. The processing conditions include concentration, residence time, solution $\mathrm{pH}$, number of successive extraction steps, etc. $^{13}$. Too concentrated EDTA solution may alter soil properties while too low concentration of EDTA solution was found unable to release the majority of the labile fractions of metals ${ }^{7}$. So, EDTA concentration should be optimized. EDTA-promoted metal removal includes a fast metal detachment from the metal-oxygen bonds and a rate limiting metal detachment from the oxide structure $^{7,12}$, weakly bound metals were first released to the liquid matrix, followed by gradually release of tightly bound metals ${ }^{12}$. 
So, there is no doubt that heavy metal removal rate influenced by washing duration and extraction steps are required.

A previous particle size separation can help soil washing obtain more impressive results. It involves removing more polluted soil particles from the rest of the soil by exploiting differences in characteristics between the metal-bearing soil particles ${ }^{13-15}$. The soil washing approach could be exceptional cost effective if the initial volume of contaminated soil was reduced ${ }^{6}$. Considering that fine particles of soil is apt to transfer with dust or enter into visceral organs of human body through hand or mouth ${ }^{16}$. Fine particles of the contaminated soil must be treated first. That is, particle size separation procedure should be conducted from coarser to fine soil particle size. However, limited effort has been made to focus on such problems so far.

The heavy metal mobility of the washed soil is increasingly used to evaluate the success of soil remediation instead of the total heavy metal content ${ }^{17}$. It is also the main concern about the EDTA application on the contaminated soil ${ }^{18}$. It should be reduced as much as possible, can be easily assessed from sequential extraction data ${ }^{19}$.

Therefore, the main aims of the current study were the following: (1) to study the effectiveness of the combination treatments of particle size separation and EDTA extraction at optimum process condition for heavy metal removal from the contaminated soil; (2) to analyze the redistribution of metals in soil once the optimized EDTA washing procedure has been carried out.

\section{EXPERIMENTAL}

The soil samples were collected from $0-30 \mathrm{~cm}$ surface at a derelict industrial site in Beijing, China, where an iron and steel work site was previously located. The collected soil samples were air-dried at room temperature $\left(22-28^{\circ} \mathrm{C}\right)$, were sieved using a sieve $(2 \mathrm{~mm})$ to remove large particles, then thoroughly mixed to ensure uniformity.

The soil sample with high level of $\mathrm{Zn}, \mathrm{Cd}$ and As was selected for this study (Table-1). Total $\mathrm{Zn}$ and $\mathrm{Cd}$ content was determined using ICP-OES (HK-2000) and ICP-MS (Agilent 7500) after acid digestion $\left(\mathrm{HNO}_{3}-\mathrm{HF}-\mathrm{HClO}_{4}\right)^{12}$. As content was determined by AFS-9800 atomic fluorescence spectrometer (Beijing Haiguang Instruments Co. Ltd) after acid digestion $\left(\mathrm{HNO}_{3}-\mathrm{H}_{2} \mathrm{O}_{2}\right)^{20}$. The CEC of the sample was determined by the ammonium acetate $\left(\mathrm{NH}_{4} \mathrm{OAc}\right)$ sodium acetate $(\mathrm{NaOAc})$ methods $^{21}$. Soil $\mathrm{pH}$ was determined by $\mathrm{pH}$ meter (pHS-3B) followed water extraction at a 5:1 $\mathrm{CaCl}_{2}(0.01 \mathrm{M})$ to soil ratio ${ }^{21}$. Organic matter per cent was determined by Walkley Black method ${ }^{21}$. The soil particle size distribution was measured by ultrasonic disperse - laser granularity analyzer (Mastersizer 2000) followed by mild boiling with $\mathrm{H}_{2} \mathrm{O}_{2}-\mathrm{HCl}-$ $\left(\mathrm{NaPO}_{3}\right)_{6}$ solution ${ }^{22}$. Quality control includes triplicate analyses, blanks and two standard reference soils.
Washing procedure: The batch tests were conducted as follows: The tubes containing $5 \mathrm{~g}$ soil sample and $15 \mathrm{~mL}$ EDTA were placed in a shaker and were shaken at a speed of 280 $\mathrm{rpm}$ at room temperature $\left(22-28{ }^{\circ} \mathrm{C}\right)$ for a given time. The suspensions were centrifuged at $5000 \mathrm{rpm}$ for $15 \mathrm{~min}$ and the supernatants were then filtered through a $0.45 \mu \mathrm{m}$ membrane for heavy metal analysis. The concentrations of $\mathrm{Zn}$ and $\mathrm{Cd}$ were measured by ICP-OES and ICP-MS, the concentration of As was measured by AFS. The $\mathrm{pH}$ of the solution after washing was measured using a $\mathrm{pH}$ meter. All tests were performed in triplicates.

In the experiment investigating different concentrations of EDTA, six different concentrations $(0.015,0.03,0.075,0.15$, $\left.0.225,0.3 \mathrm{mmol} \mathrm{g}^{-1}\right)$ were chosen $(\mathrm{L} / \mathrm{S}=10,6 \mathrm{~h})$. The kinetic study was performed in tubes containing $2 \mathrm{~g}$ soil and $20 \mathrm{~mL}$ of $0.075 \mathrm{mM}$ EDTA that were shaken for different times: 1, $1.5,2,2.5,3,4,5$ and $6 \mathrm{~h}$. For the consecutive extractions, $2 \mathrm{~g}$ soil was extracted for $3 \mathrm{~h}$. The suspension was centrifuged and the solution removed. The new solution was added to the treated soil and the tubes returned to the shaker. A total of four consecutive $3 \mathrm{~h}$ extractions were carried out, with $20 \mathrm{~mL} 0.075$ mM EDTA for each.

In investigating the different physical sieving methods, the soil before and after EDTA washing were sieved into five particle size ranges: $<0.063 \mathrm{~mm}, 0.063-0.15 \mathrm{~mm}, 0.15-0.59$ $\mathrm{mm}, 0.59-1 \mathrm{~mm}$ and $1-2 \mathrm{~mm}$. Each soil particle size range was weighed and digested for metal analysis. The evaluation process was conducted as follows: First, to calculate heavy metal removal rates for different particle size range, respectively (1). Second, to cumulate heavy metal removal rates from fine particle to coarse particle range (2).

$$
\begin{gathered}
\mathrm{R}=100 \% \frac{\left(\mathrm{C}_{\mathrm{i}} \times \mathrm{m}_{\mathrm{i}}-\mathrm{C}_{\mathrm{j}} \times \mathrm{m}_{\mathrm{j}}\right)}{\mathrm{C}_{\mathrm{i}} \times \mathrm{m}_{\mathrm{i}}} \\
\mathrm{CR}=\mathrm{R}_{<0.063 \mathrm{~mm}}+\ldots+\mathrm{R}_{\mathrm{i}}
\end{gathered}
$$

In the formula, $\mathrm{R}$ is the metal removal rate for one of the five particle size ranges. $C_{i}$ and $C_{j}$ were the heavy metal concentration of the particle size range of the soil before and after washing. $m_{i}$ and $m_{j}$ were their mass ratios before and after washing. $R_{i}$ is the metal removal rate of a coarser particle size range of the soil. $\mathrm{CR}$ is the cumulative metal removal rate for the specified particle size range of the soil.

Sequential extraction procedure: A sequential extraction procedure was selected to ascertain the distribution of the metals in the soils before and after the combination treatment of particle size separation and EDTA extraction. The sequential extraction procedure carried out in this study ${ }^{23}$ was as follows: $1 \mathrm{~g}$ of soil sample and $40 \mathrm{~mL}$ of extraction solution were used in each extraction step. Concentrations for the exchangeable fraction, $\mathrm{Fe} / \mathrm{Mn}$ fraction, $\mathrm{O} / \mathrm{S}$ fraction and residue fraction were obtained by analyzing the supernatants extracted with $0.11 \mathrm{M}$ acetic acid (shaken for $16 \mathrm{~h}$ ), $0.1 \mathrm{M}$ hydroxylamine

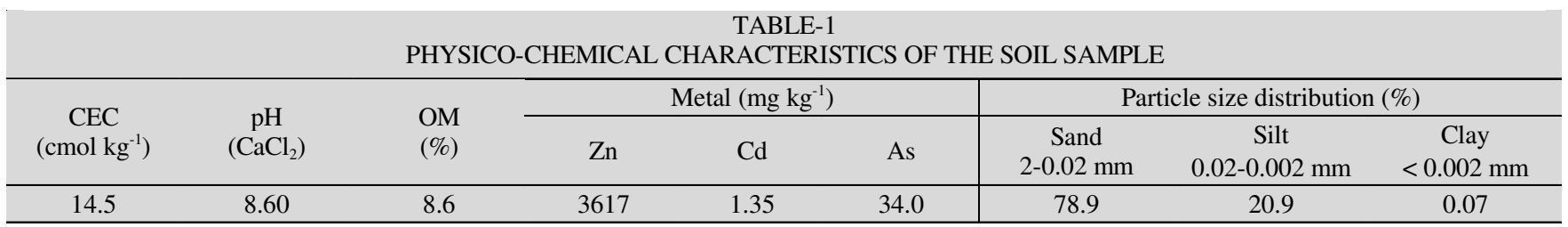


hydrochloride (acidified with $\mathrm{HNO}_{3}$ to $\mathrm{pH}$ 2) (16 h), $10 \mathrm{~mL}$ of $30 \%(\mathrm{v} / \mathrm{v}) \mathrm{H}_{2} \mathrm{O}_{2}(3 \mathrm{~h})+1 \mathrm{M}$ ammonium acetate $(16 \mathrm{~h})$ and pseudo-total acid digestion $\left(\mathrm{HNO}_{3}+\mathrm{HF}\right)$, respectively. Between each sequential extraction, the solid residue was rinsed twice with $20 \mathrm{~mL}$ of bi-distilled water, shaken and centrifuged. The liquid supernatant was discarded.

Data analysis: Microsoft Excel 2003 software was used to analyze experiment data and create necessary graph. Heavy metal removal rate $(\%)$ and heavy metal removal efficiency $\left(\mathrm{mg} \mathrm{mol}^{-1}\right)$ were calculated as follows:

Metal removal rate $(\%)=$ Metal removal amount $\left(\mathrm{mg} \mathrm{kg}^{-1}\right)$ / Initial metal amount in soil $\left(\mathrm{mg} \mathrm{kg}^{-1}\right)$

Metal removal efficiency $\left(\mathrm{mg} \mathrm{mol}^{-1}\right)=$ Metal removal amount per $\mathrm{kg}$ of soil $\left(\mathrm{mg} \mathrm{kg}^{-1}\right) /$ Moles of washing agent consumed per $\mathrm{kg}$ of soil $\left(\mathrm{mol} \mathrm{kg}^{-1}\right)$

\section{RESULTS AND DISCUSSION}

Effects of process optimization on EDTA extraction effectiveness of heavy metals: The results are shown in Fig. 1. The removal rates of $\mathrm{Zn}, \mathrm{Cd}$ and As increased with increasing EDTA concentration but their removal efficiency as well as solution $\mathrm{pH}$ decreased. The removal rates (\%) of $\mathrm{Zn}, \mathrm{Cd}$ and As were $22,4.3$ and $1.9 \%$, respectively at $0.015 \mathrm{mmol} \mathrm{g}^{-1}$. Increased to $49.9,17.1$ and $7.88 \%$ at $0.075 \mathrm{mmol} \mathrm{g}^{-1}$. Further increased to 77, 23 and $20 \%$ at $0.3 \mathrm{mmol} \mathrm{g}^{-1}$. However, the removal efficiency of $\mathrm{Zn}, \mathrm{Cd}$ and As decreased from 0.015 to $0.3 \mathrm{mmol} \mathrm{g}^{-1}$ (from 52 to $9 \%$ for $\mathrm{Zn}$, from 3.8 to 1.0 for $\mathrm{Cd}$ and from 43 to $22 \%$ for As). And the decrease for $\mathrm{Cd}$ and $\mathrm{As}$ were more apparent in the concentration range 0.075-0.3 mmol $\mathrm{g}^{-1}$. The results indicated that EDTA concentration had positive effect on metal removal rate but a negative effect on metal removal efficiency. This was consistent with the findings of Andrade $e t a l .^{24}$. As EDTA concentration increases, only a small portion was transformed into metal-chelate complexes, while the excess might form complexes with some mineral elements like $\mathrm{Fe}, \mathrm{Ca}$ and $\mathrm{Al}$, etc. The solution $\mathrm{pH}$ decreased from 0.015 to $0.3 \mathrm{mmol} \mathrm{g}^{-1}$ (from 7.47 to 4.83 ). The $\mathrm{pH}$ at $0.075 \mathrm{mmol} \mathrm{g}^{-1}$ was 6.67. And it decreased sharply to 5.03 as the concentration increased to $0.15 \mathrm{mmol} \mathrm{g}^{-1}$. In general, a lower solution $\mathrm{pH}$ resulted in a higher heavy metal removal rates. However, too acidic or too alkaline solution would damage soil chemical and physical structure as well as the soil microbial activity ${ }^{25}$. So, in practice, the solution $\mathrm{pH}$ should better be controlled in neutral. By comprehensive consideration of the heavy metal removal rate and efficiency as well as the solution $\mathrm{pH}, 0.075$ mmol g-1 was screened out as the EDTA concentration for further study.

The kinetic experiment results (Fig. 1) indicated that EDTA induced a rapid metal release within $3 \mathrm{~h}$ followed by a subsequent slow metal release that occurred over the rest $3 \mathrm{~h}$. This tendency for $\mathrm{Zn}$ is more obvious than for $\mathrm{Cd}$ and As. The removal rates reached a relatively higher level at $3 \mathrm{~h}$ when 48 $\%$ of $\mathrm{Zn}, 15 \%$ of $\mathrm{Cd}$ and $7.3 \%$ of As was removed. After that, their removal rates almost reached a plateau with increasing duration time. The results similar with $\mathrm{Xu}$ and $\mathrm{Xia}^{26}$ who observed that the extraction of $\mathrm{Cd}$ reaching equilibrium within a contact time of $2 \mathrm{~h}$ and the extraction of $\mathrm{Zn}$ reaching equilibrium within $4 \mathrm{~h}$. Further increase duration time had little effect on metal removal rate. So, an extraction time of $3 \mathrm{~h}$ was chosen for the rest of this study.

Successive washing greatly increased the removal rates of heavy metals from the contaminated soil, but by different

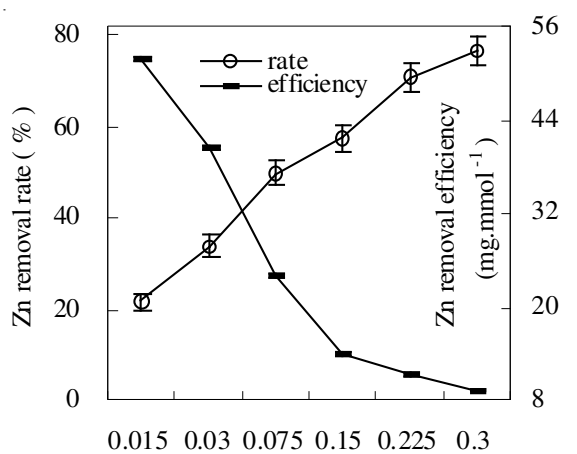

EDTA concentration ( mmol. $\mathrm{g}^{-1}$ )

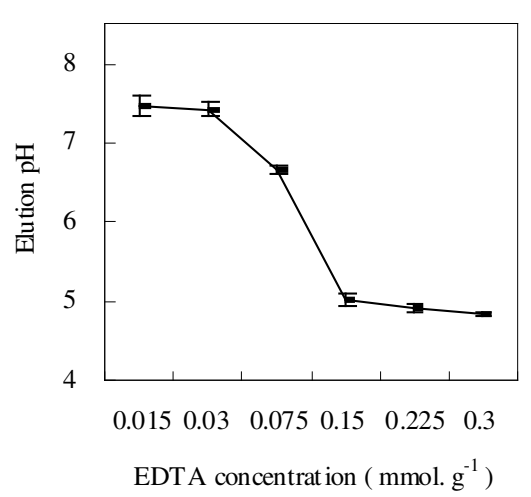

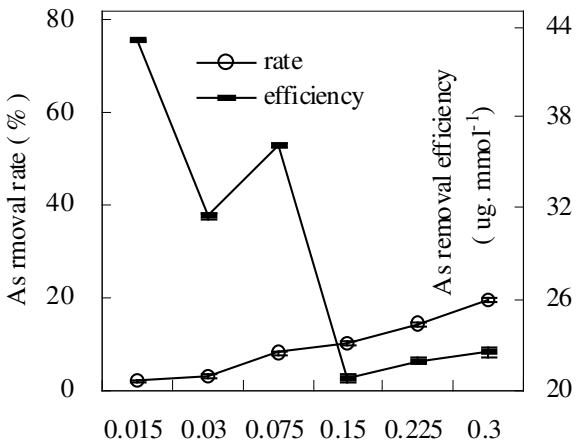

EDTA concentration ( mmol. $\mathrm{g}^{-1}$ )

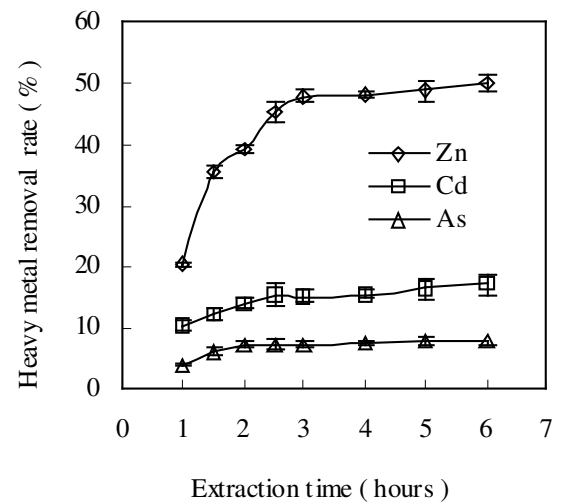

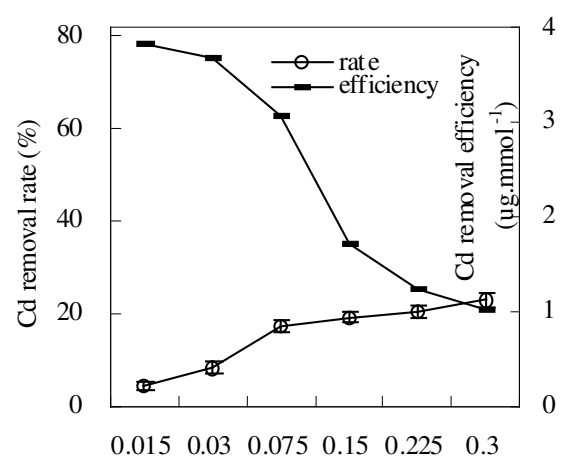

EDTA concentration ( mmol. $\mathrm{g}^{-1}$ )

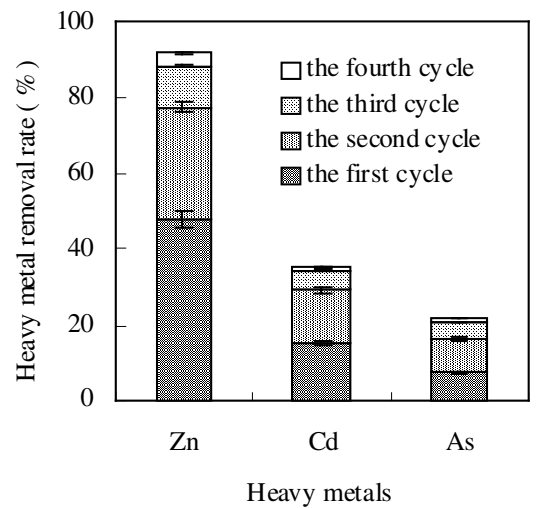

Fig. 1. Influence of selected process parameters on EDTA extraction effectiveness of heavy metals 
extents for different washing cycles. The second cycle is especially effective, followed by the third cycle. The cumulative removal rates of $\mathrm{Zn}, \mathrm{Cd}$ and As from the soil were 48, 15 and $7 \%$ for the first cycle; and 77, 29 and $16 \%$ for the two successive cycles and 89,35 and $20 \%$ for the three successive cycles. After that, the increase of metal removal rates was still observed but could be negligible. Our results consistent with Zou and Qiu ${ }^{12}$ who points out that increase washing cycles is helpful to the dissolution of metal-bearing particles and the removal of residue metal chelates trapped in the soil. So, an extraction cycle of 3 was chosen for the rest of the study.

When EDTA extraction under the optimized process conditions ( $0.075 \mathrm{mmol} \mathrm{g}^{-1}, 3 \mathrm{~h}$ and 3 cycles), $\mathrm{Zn}, \mathrm{Cd}$ and $\mathrm{As}$ removal rates from the contaminated soil were $91.7,35.5$ and $21.4 \%$, respectively.

Effects of particle size separation on EDTA extraction effectiveness of heavy metals: Sieve out the particle size range of 1-2 $\mathrm{mm}$ from the rest of the contaminated soil reduced weight of the treated soil to a great extent $(21.7 \%)$. While not significantly lowered $\mathrm{Zn}, \mathrm{Cd}$ and As removal rates and was thus recommended. From Table-2, we can see that the EDTA at selected process conditions could decontaminate $\mathrm{Zn}, \mathrm{Cd}$ and As from the whole particle size range of the soil. Not significantly influence their particle size distribution patterns in the contaminated soil. $\mathrm{Zn}$ and $\mathrm{Cd}$ are mainly distributed in fine particle size range of the soil, very few amount distributed in coarse particle size range. As is enriched in both fine and coarse particle size range of the soil, very few amount distributed in medium size range $0.15-0.59 \mathrm{~mm}$. In terms of metal removal rates, treating $<0.15 \mathrm{~mm}$ soil resulted in relatively not good for $\mathrm{Zn}, \mathrm{Cd}$ and As removal effect (their rates were 41.4, 19.6 and $13.4 \%$, respectively). Interestingly, there were no sharp differences in $\mathrm{Zn}, \mathrm{Cd}$ and As removal rates between $<2 \mathrm{~mm}$ and $<1 \mathrm{~mm}$ range of the contaminated soil. $\mathrm{Zn}, \mathrm{Cd}$ and $\mathrm{As}$ removal rates for $<2 \mathrm{~mm}$ soil were $93.8,36.5$ and $40.4 \%$, respectively. For $<1 \mathrm{~mm}$ soil were $82.7,33.2$ and $32 \%$, respectively. However, by compare their weights, we observed that the weight of $<1 \mathrm{~mm}$ soil was greatly lower than that of $<$ $2 \mathrm{~mm}$ soil, by a percentage of $21.7 \%$. Thus, it is quite necessary to sieve out the particle size range of $1-2 \mathrm{~mm}$ from the contaminated soil. Since sieve out the particle size range of $0.59-1 \mathrm{~mm}$ from the contaminated soil would greatly reduce $\mathrm{Zn}$ and As removal rates, further soil volume reduction was not recommended.

Heavy metal mobility of the washed soil: The distribution of $\mathrm{Zn}, \mathrm{Cd}$ and As in the soil determined before and after treating the soils $(<1 \mathrm{~mm})$ with EDTA are shown in Fig. 2. After the EDTA extraction, the proportions of $\mathrm{Zn}, \mathrm{Cd}$ and $\mathrm{As}$ in the EXC (exchangeable) and Fe/Mn fraction decreased. And their proportions in the residue fraction considerably increased. As a consequence, heavy metal risk of the soil could be avoided. Before washing, Zn was predominantly distributed in the Fe/ $\mathrm{Mn}$ fraction, next came residue and $\mathrm{O} / \mathrm{S}$ fraction; $\mathrm{Cd}$ and $\mathrm{As}$ were predominantly distributed in the residue fraction, next $\mathrm{Fe} / \mathrm{Mn}$ and $\mathrm{O} / \mathrm{S}$ fraction. After washing, $\mathrm{Zn}$ and $\mathrm{Cd}$ was predominantly distributed in the residue fraction, next $\mathrm{O} / \mathrm{S}$ and $\mathrm{Fe} / \mathrm{Mn}$ fraction; arsenic was predominantly distributed in the residue fraction, next Fe/Mn and $\mathrm{O} / \mathrm{S}$ fraction. Their proportion in exchangeable fraction were all negligible $(<1 \%)$. Though $\mathrm{Zn}, \mathrm{Cd}$ and As content in all four fractions of the soil were reduced, their decreasing range in $\mathrm{Fe} / \mathrm{Mn}$ fraction were the highest (48, 49 and $82 \%$, respectively). The reason might lies in the fact that formation of EDTA-metal chelate could weaken the bonding strength between Fe/Mn oxides and heavy metals ${ }^{27}$.

TABLE-2

REMOVAL RATES OF Zn, Cd AND As CALCULATED ACCORDING TO DIFFERENT PARTICLE SIZE SEPARATION TECHNIQUES

\begin{tabular}{|c|c|c|c|c|c|c|c|c|c|c|c|c|c|}
\hline \multirow{2}{*}{$\begin{array}{c}\text { Particle } \\
\text { size }(\mathrm{mm})\end{array}$} & \multicolumn{5}{|c|}{ Before washing } & \multicolumn{5}{|c|}{ After washing } & \multicolumn{3}{|c|}{ Cumulative removal rate $(\%)$} \\
\hline & $\begin{array}{l}\text { Mass } \\
\text { (g) }\end{array}$ & $\begin{array}{l}\text { Ratio } \\
(\%)\end{array}$ & $\mathrm{Zn}$ & $\mathrm{Cd}$ & As & $\begin{array}{c}\text { Mass } \\
(\mathrm{g})\end{array}$ & $\begin{array}{c}\text { Ratio } \\
(\%)\end{array}$ & $\mathrm{Zn}$ & $\mathrm{Cd}$ & As & $\mathrm{Zn}$ & $\mathrm{Cd}$ & As \\
\hline$<0.063$ & 4.56 & 8.1 & 6794 & 2.39 & 36.7 & 4.21 & 7.7 & 1156 & 1.49 & 37.8 & 16.0 & 8.0 & 1.0 \\
\hline $0.063-0.15$ & 9.64 & 17.1 & 4419 & 1.48 & 34.9 & 9.13 & 16.7 & 105 & 0.85 & 14.1 & 41.4 & 19.6 & 13.4 \\
\hline $0.15-0.59$ & 18.5 & 32.9 & 2886 & 1.02 & 20.3 & 17.3 & 31.5 & 139 & 0.76 & 11.7 & 72.5 & 29.7 & 24.2 \\
\hline $0.59-1$ & 11.4 & 20.2 & 1558 & 0.56 & 31.7 & 11.8 & 21.5 & 85.0 & 0.37 & 19.9 & 82.7 & 33.2 & 32.0 \\
\hline $1-2$ & 12.2 & 21.7 & 1561 & 0.53 & 30.2 & 12.5 & 22.7 & 78.9 & 0.37 & 18.8 & 93.8 & 36.5 & 40.4 \\
\hline Total & 56.3 & 100 & 3617 & 1.35 & 34.4 & 54.8 & 100 & 389 & 0.91 & 25 & 97.1 & 46.0 & 35.0 \\
\hline
\end{tabular}
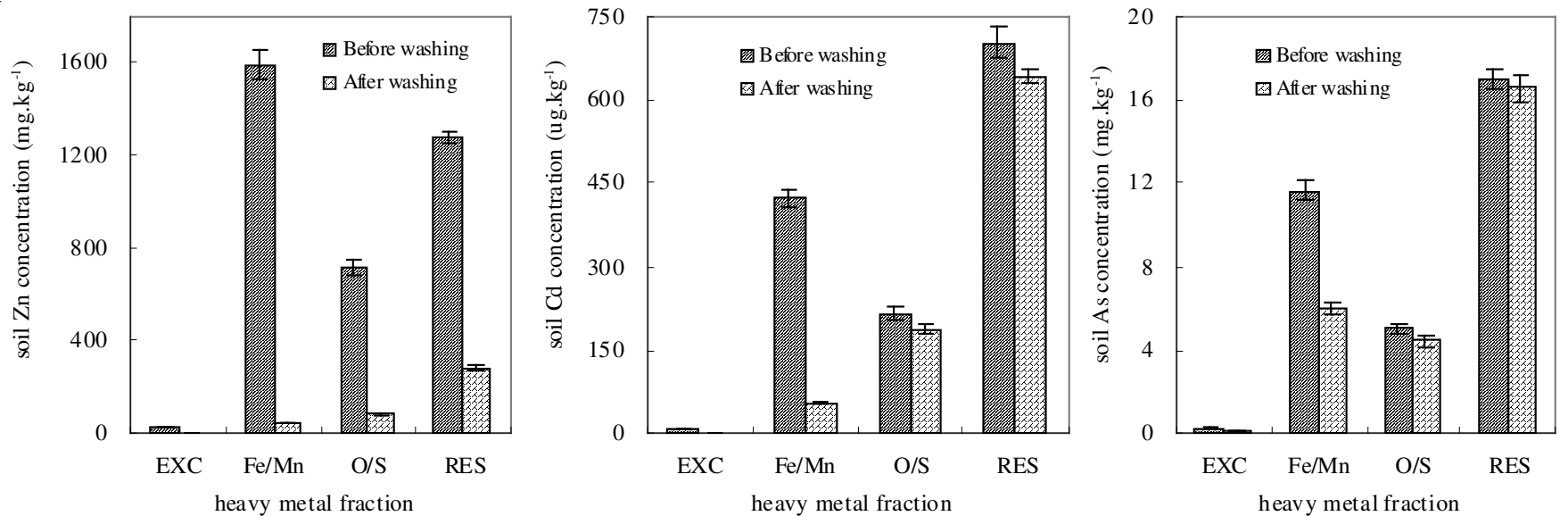

Fig. 2. Speciation distributions of heavy metals before and after soil washing 


\section{Conclusion}

This work showed that the optimization of selected process parameters $\left(0.075 \mathrm{mmol} \mathrm{g}^{-1}, 3 \mathrm{~h}, 3\right.$ cycles $)$ made EDTA washing economically viable and environmentally friendly. Due to the other process parameters also affecting the effectiveness of EDTA washing, further search for the optimized conditions is possible. From the results of present study, coupling the particle size separation and process optimization could help to expedite the optimization process and reduce the laborious trial works. The EDTA washing procedure established could remove $91.7 \% \mathrm{Zn}, 35.5 \% \mathrm{Cd}$ and $21.4 \%$ As, respectively, from the contaminated soil. Fractionation analysis results indicated that EDTA was able to extract exchangeable and $\mathrm{Fe} / \mathrm{Mn}$ fraction. It could also extract certain amount of $\mathrm{Zn}$ from the $\mathrm{O} / \mathrm{S}$ and residue fraction. Which implied that the extractable metals were not so strongly fixed to the $\mathrm{O} / \mathrm{S}$ and residue fraction as previously supposed. However, because of the careful control on the EDTA washing process, the proportions of $\mathrm{Zn}, \mathrm{Cd}$ and As in the RES and Fe/Mn fraction greatly reduced; while the proportions of $\mathrm{Zn}, \mathrm{Cd}$ in $\mathrm{O} / \mathrm{S}$ and residue fraction and $\mathrm{As}$ in residue fraction considerably increased, which indicated that heavy metal risk of the soil could be avoided. EDTA washing procedure requires careful control so as to not only efficiently decontaminate metals from the soil but also prevent displacement of metal contamination from soil to groundwater.

\section{ACKNOWLEDGEMENTS}

This paper is supported by the National Natural Science Foundation of China (No. U0833004) and the Special Research fund for the public benefits sponsored by Ministry of Environmental Protection of the People's Republic of China (No. 201009015).

\section{REFERENCES}

1. A.J. Harber and R.A. Forth, Environ. Geol., 40, 324 (2001).

2. R.L. Qiu, Z.L. Zou, Z.H. Zhao, W.H. Zhang, T. Zhang, H.Y. Dong and X.G. Wei, J. Soils Sed., 10, 45 (2010).
3. B.W. Zhao and B. Jiang, Asian J. Chem., 23, 3859 (2011).

4. Federal Remediation Technologies Roundtable, Compiled from Remediation Technology Screening Matrix and Reference Guide, edn. 4. Available at http://www.frtr.gov/matrix2/section1/toc.html.

5. K. Maturi and K.R. Reddy, Soil Sed. Contam., 17, 586 (2008).

6. J.M. Michael, J. Hazard. Mater, 66, 119 (1999).

7. W.H. Zhang, H. Huang and F.F. Tan, H. Wang and R.L. Qiu, J. Hazard. Mater., 173, 369 (2010).

8. W.A. Norvell, in eds.: J.J. Mortvedt, Cox, F.R. Shuman and L.M. Welch, Reactions of Metal Chelates in Soils and Nutrient Solutions, Micronutrients In agriculture, Soil Science Society of America, Wiscosin, Madison, edn. 2, pp. 187-227 (1991).

9. B. Sun, F.J. Zhao, E. Lombi and S.P. McGrath, Environ. Pollut., 113, 111 (2001).

10. W.H. Zhang, D.C.W. Tsang and I.M.C. Lo, J. Hazard. Mater, 155, 433 (2008)

11. T.T. Lim, J.H. Tay and J.-Y. Wang, J. Environ. Eng., 130, 59 (2004).

12. Z.L. Zou, R.L. Qiu, W.H. Zhang, H.Y. Dong, Z.H. Zhao, T. Zhang, X.G. Wei and X.D. Cai, Environ. Pollut., 157, 229 (2009).

13. G. Dermont, M. Bergeron, G. Mercier and M. Richer-Laflèche, J. Hazard. Mater., 152, 1 (2008).

14. D. Lestan, C.L. Luo and X.-D. Li, Environ. Pollut., 153, 3 (2008).

15. C. Sierra, J.R. Gallego, E. Afif, J.M. Menéndez-Aguado and F. GonzálezCoto, J. Hazard. Mater, 180, 602 (2010).

16. H.M. Zhang and L.P. Wang, Guang Dong Wei Liang Yuan Su Ke Xue, 14, 14 (2007).

17. J. Kumpiene, A. Lagerkvist and C. Maurice, J. Waste Manag., 28, 215 (2008).

18. European Chemical Bureau, European Union Risk Assessment Report on $\mathrm{Na}_{4}$ EDTA, Office for Official Publications of the European Communities, Italy (2004).

19. L.Q. Ma and G.N. Rao, J. Environ. Qual., 26, 259 (1997).

20. M. Lei, T.B. Chen, Z.C. Huang, X.Y. Liao, Y.R. Liu, G.D. Zheng and Q.R. Chang, Acta Ecol. Sin., 25, 1146 (2005).

21. D.W. Nelson and L.E. Sommers, Total Carbon, Organic Carbon and Organic Matter, Methods of Soil Analysis, Part 3 - Chemical Methods, pp. 961-1010 (1996).

22. M. Ryzak and A. Bieganowski, J. Plant Nutr. Soil Sci., 174, 624 (2011).

23. A. Barona, I. Aranguiz and A. Elias, Environ. Pollut., 113, 79 (2001).

24. M.D. Andrade, S.O. Prasher and W.H. Hendershot, Environ. Pollut., 147, 781 (2007).

25. W. Zhang and I.M.C. Lo, J. Environ. Eng., 132, 1282 (2006).

26. C. Xu and B.C. Xia, J. Agro-Environ. Sci., 28, 1585 (2009).

27. C. Chaiyaraksa and N. Sriwiriyanuphap, Chemosphere, 56, 1129 (2004). 